\title{
COORDENAÇÃO DO TRABALHO PEDAGÓGICO: DO PROJETO POLÍTICO- PEDAGÓGICO AO COTIDIANO DA SALA DE AULA
}

\section{Coordination of Pedagogical Work: from the Political-Pedagogical Project to the Daily Life of the Classroom}

Arthur Breno Stürmer ${ }^{1}$

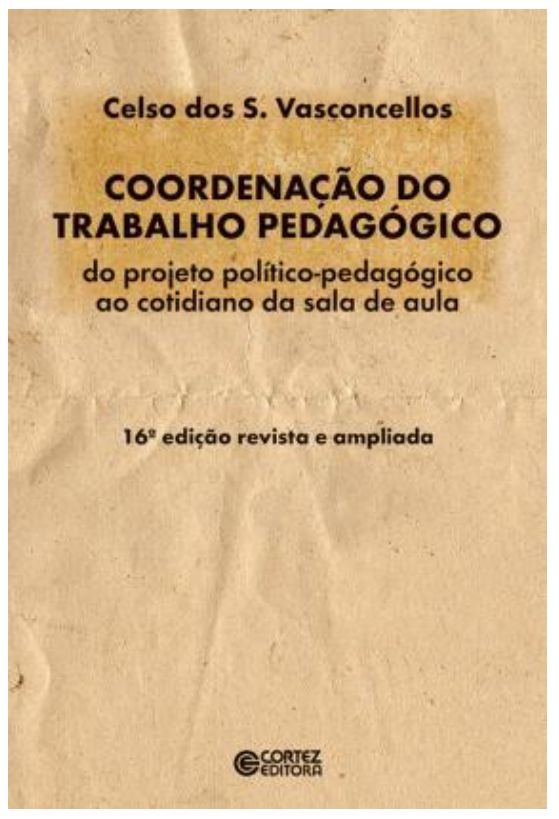

\begin{abstract}
VASCONCELLOS, Celso dos Santos.
Coordenação do Trabalho Pedagógico: do projeto político-pedagógico ao cotidiano da sala de aula. 16. ed. revista e ampliada. São Paulo: Cortez, 2019.
\end{abstract}

Cada área do conhecimento tem seus clássicos. A educação tem vários deles. Coordenação do Trabalho Pedagógico: do projeto político-pedagógico ao cotidiano da sala de aula certamente está entre os grandes. Desde que foi dado ao público, originalmente em 2002, atravessou quase duas décadas orientando o debate na academia e na escola, na formação inicial e continuada, entre gestores, docentes, pesquisadores. Abordando temas como o planejamento educacional, currículo, ensino-aprendizagem, avaliação e outros, tornou-se uma referência obrigatória para se pensar e se fazer educação, especialmente quando das discussões em torno da gestão democrática do ensino público, construção do projeto político-pedagógico, diretrizes curriculares nacionais, planos de formação de professores, plano nacional de educação, dentre outros.

A presente obra traz a $16^{a}$ edição revisada, atualizada e ampliada, cujo prefácio convida à leitura de textos que podem qualificar o debate sobre questões da ordem do dia. Em assim sendo, Coordenação do Trabalho Pedagógico permanecerá com esse papel relevante, especialmente para fazer frente ao desmonte das políticas públicas de educação, à desvalorização do professor e do trabalho pedagógico, bem como servir de aporte à reflexão

\footnotetext{
${ }^{1}$ Doutor. Especialista em Gestão Educacional e em Docência na Educação Básica. Licenciado em Pedagogia e em Geografia. Docente do Instituto Federal de Alagoas. Orcid iD: https://orcid.org/0000-0002-0510-8454. E-mail: arthur.sturmer@ifal.edu.br
} 
sobre as implicações que as novas formas de ensino (remoto, híbrido, não presencial...) trouxeram para a coordenação do trabalho pedagógico ${ }^{2}$.

Celso dos Santos Vasconcellos, Doutor em Educação pela Universidade de São Paulo (USP), pesquisador e renomado conferencista brasileiro dedicado à temática do planejamento educacional, conquistou lugar no campo educacional com seu pensamento crítico e abordagem dialética dos assuntos que mais dizem respeito ao trabalho pedagógico. Sempre atento às grandes questões nacionais, firmou-se entre aqueles que não fogem aos debates. Sua concepção de educação humanizadora e emancipadora o coloca como representante da pedagogia progressista, defendendo - nas suas palavras - a mudança, inovação e transformação enquanto busca e compromisso. Na obra em tela, o autor mostra toda a experiência de conferencista e especialista em educação, ou seja, como aquele que passeia com propriedade ímpar por inúmeros assuntos relacionados à teoria educacional e à pedagogia. Sempre com uma linguagem acessível ao público em geral, propõe-se a trazer textos autônomos que servem muito bem aos estudantes em formação inicial, profissionais da educação em formação continuada e também aos pesquisadores da área da educação, incluindo pós-graduandos.

A obra está segmentada em onze capítulos para dar conta de várias facetas do trabalho pedagógico, que vem a ser o eixo articulador dos temas abordados sob a perspectiva da gestão democrática e libertadora. No prefácio, Vasconcellos (2019) esclarece de pronto a dúvida que paira desde o título à capa: de quem é a responsabilidade do trabalho pedagógico (na escola)? Para ele, "a coordenação do trabalho pedagógico [...] tem a ver com todos os sujeitos". E completa: o trabalho pedagógico diz respeito a "todas as instâncias formativas no interior da escola" (VASCONCELLOS, 2019, p. 14), ou seja, do projeto político-pedagógico à sala de aula.

O capítulo 1 discute o trabalho pedagógico relacionado ao projeto político-pedagógico, partindo do seu conceito e fundamentação teórico-metodológica e indo até os procedimentos de construção, execução e avaliação do projeto político-pedagógico. Diz: "não podemos perder de vista o essencial [...]: o mais importante não é ter Projeto e sim transformar a prática!" (VASCONCELLOS, 2019, p. 65).

Os capítulos 2, 3 e 4 destacam o trabalho pedagógico, respectivamente, na direção, orientação e supervisão. A direção (e a equipe diretiva) (capítulo 2) tem compromisso com a gestão democrática, o que requer mudanças nas práticas pedagógicas e na relação da escola com a comunidade e sociedade. Assim, o trabalho pedagógico gira em torno da integração e articulação dos segmentos internos e externos da escola, contudo sua grande tarefa é "fazer a escola funcionar pautada num projeto coletivo" (VASCONCELLOS, 2019, p. 88).

Já à orientação educacional (capítulo 3) fica reservada a mediação das relações, com um fim determinado - a mudança: "os especialistas devem se especializar em mudança!" (VASCONCELLOS, 2019, p. 102, grifo do autor). Então seu trabalho pedagógico parte de onde o sujeito está para empreender tarefas como o resgate da identidade do professorado, a promoção dos alunos à condição de sujeitos do seu processo de educação, além de prestar orientação profissional/vocacional e outros. Em especial, Vasconcellos (2019) ressalta o papel de superar as práticas isoladas por meio do trabalho coletivo com "instrumentos metodológicos"

\footnotetext{
${ }^{2}$ As formas de ensino provisórias instaladas nas redes de ensino, em função da crise pandêmica do Covid-19 (ERE, REDE, REANP, etc.), representam grandes desafios à coordenação do trabalho pedagógico, para os quais a obra Coordenação do Trabalho Pedagógico pode ser um guia, seja ao trazer alternativas viáveis para a gestão do trabalho pedagógico em sala de aula, seja pelas considerações acerca das potencialidades e dos equívocos em relação às metodologias ativas.
} 
como: projeto político-pedagógico, representantes de classe, reunião pedagógica semanal, conselho de classe participativo e conselho de escola.

Por sua vez, a supervisão/coordenação pedagógica (capítulo 4) exerce, segundo Vasconcellos (2019), a articulação do projeto político-pedagógico no campo pedagógico "organizando a reflexão, a participação e os meios para a concretização do mesmo" (VASCONCELLOS, 2019, p. 129). Seu foco são os processos de ensino-aprendizagem. O que lhe for à contramão, desumaniza a escola: a reprodução da ideologia dominante, o autoritarismo, o conhecimento desvinculado da realidade, a evasão, a lógica classificatória e excludente e a discriminação social. Portanto, a supervisão liga-se também ao trabalho de formação dos professores, de modo individual e coletivo, visando à relação professor-aluno. Melhor dito, o supervisor é mediador que auxilia os professores na sua prática pedagógica, contribuindo para “'outra-visão'!" (VASCONCELLOS, 2019, p. 132, grifo do autor).

O capítulo 5 é dedicado ao trabalho coletivo. Fica claro ao leitor que o trabalho pedagógico discutido até então passa pela visão da equipe diretiva, agora ressaltada por ser, em última análise, a responsável por dar contorno coletivo ao trabalho pedagógico. Vasconcellos (2019) o localiza especialmente na "reunião pedagógica semanal", essa forma de trabalho que é "condição mesma para a concretização de uma prática transformadora" (VASCONCELLOS, 2019, p. 174). E se essa proposta é ter a prática como referência à reflexão, para posterior intervenção (ação-reflexão-ação), as reuniões pedagógicas servem à construção da práxis. De acordo com o autor, "fazer do trabalho coletivo um espaço de práxis é tarefa árdua", que depende da "parceria entre equipe [diretiva] e professores na sua construção" (VASCONCELLOS, 2019, p. 183).

No capítulo 6, a coordenação do trabalho pedagógico tem como foco a organização do currículo estruturado em ciclos de formação. Estes são defendidos por ajudarem a desenvolver uma nova cultura institucional aberta à criatividade aos "novos possíveis" da práxis educacional (VASCONCELLOS, 2019, p. 199, grifo do autor). O autor trata da origem e conceito dos ciclos de formação e explica como organizar o currículo nestes moldes, privilegiando o fluxo da experiência do aluno ao invés de tomar como parâmetro um programa. Novamente, Vasconcellos (2019) retoma o debate sobre a mudança, sugerindo etapas do processo de implantação dos ciclos de formação, inclusive apontando possíveis equívocos na construção do novo currículo.

O capítulo 7 se debruça diante do trabalho pedagógico mais próximo da sala de aula e do cotidiano, aos quais os professores estão habituados. Parecendo falar diretamente ao professor, distingue o projeto de ensino-aprendizagem (ou plano de ensino, de curso ou de estudos) como o cerne de sua atuação, ou seja, a organização da proposta para o trabalho em sala de aula como o campo da práxis docente. De maneira didática, Vasconcellos (2019) sintetiza os principais aspectos da construção dos planos de ensino, quais sejam: a vinculação ao projeto político-pedagógico da escola; a integração com a área, curso e escola; e a visão dialética sobre o planejamento. Salienta, ainda, a função articuladora da equipe de coordenação para alterar a prática do professor, implicando no acompanhamento e não apenas na fiscalização e controle formal e burocrático. Para tanto, lista algumas iniciativas que resultam na maior interação de caráter mediador.

O capítulo 8 é menos pontual que o anterior, uma vez que precisa destrinchar o método expositivo, extraindo os prós e contras da aula expositiva. Recorre-se à crítica construtiva que aproveita o núcleo de bom senso da educação tradicional e propõe a exposição dialogada, pela qual há a exigência de uma qualidade interna da fala e uma importância quanto à qualidade do vínculo da fala com o outro. É quando surge a "exposição provocativa" e a "necessidade de 
atividade do educando" (VASCONCELLOS, 2019, p. 244; 246) como elementos de mudança. Quer dizer, interessa mais, sem dúvida, a postura do professor em sua intencionalidade e leitura crítica da realidade, que a própria técnica em si. É assim que o autor conclui que há espaço para a aula expositiva, desde que esteja a serviço da mudança das práticas mecanicistas, burocráticas e bancárias no ensino.

O capítulo 9 segue com problemas que desembocam na sala de aula. A (in)disciplina é tratada em um segmento que remete a outras leituras e dialoga com a realidade e o contexto atual. Para Vasconcellos (2019), há inúmeras dimensões deste problema complexo, dentre as quais a ação institucional que favoreça a construção de uma nova disciplina na sala de aula e na escola. Tais dimensões envolvem a estrutura de ação, o contexto da ação e a participação do aluno, enfim, depende: a) do projeto político-pedagógico que resgate o sentido para o estudo e que contemple qual disciplina se deseja; b) do projeto de ensino-aprendizagem que explicite o sentido da matéria a ser estudada, assuma metodologias participativas e preveja o contrato didático; c) do contrato didático ou combinado entre professor com um coletivo de alunos, que traga as regras, possibilidades, limites, expectativas, responsabilidades, sanções e outros; d) das condições adequadas de trabalho na escola para alunos e educadores; e) da definição dos papéis; f) do fortalecimento do professor.

A disciplina, logo, é entendida como algo que se constrói entre os diferentes sujeitos da relação pedagógica, sendo favorecida pela clareza de objetivos, participação e organização do trabalho didático. Também há possibilidades de intervenção para o professor, indicadas pelo autor em oitos pontos, bem como medidas para a auto-organização do aluno, a fim de que atinja um grau de autodisciplina. De acordo com a perspectiva dialético-libertadora adotada pelo autor, é preciso haver a participação do aluno em sala de aula, na vida da escola, desenvolver um sentido solidário de aprendizagem e compreender que o estudo é um trabalho.

O capítulo 10 toca em um assunto candente na educação brasileira: a avaliação por competências, tomada como classificatória e excludente quando posta diante da avaliação hermenêutico-quântica. O autor propõe "o esforço de interpretação da produção do aluno (e do contexto)" (VASCONCELLOS, 2019, p. 267), a reflexão sobre o nosso olhar, a importância do diálogo, a escuta, o reconhecimento do outro e as aproximações sucessivas para a construção do sentido. Ainda, chama a atenção para a avaliação, que incide sobre "uma zona de probabilidade e não uma definição precisa", do mesmo jeito que "a tentativa de medir a realidade não é neutra, acaba por alterá-la" (VASCONCELLOS, 2019, p. 268). Por isso, aqui o autor lembra o cuidado, atenção e humildade como elementos de uma mudança de postura do professor.

O capítulo 11 fecha uma série de discussões com um tom de denúncia acerca das distorções introduzidas pelos exames, no cotidiano escolar. Vasconcellos (2019) traz à baila "a mão invisível" que força a escola a não mudar a prática pedagógica tradicional, conteudista e repetitiva ao aderir ao formalismo pedagógico em cima de conteúdos (distorção pedagógica) e à seletividade social da prática classificatória (distorção ético-política) ensejada pelos exames (de tipo Prova Brasil, Provinha Brasil, Saeb, Encceja, Enem e outros). Eles merecem as vistas do autor por se constituírem em parâmetros do currículo escolar e demandarem muito trabalho pedagógico, razão pela qual oferece pontos de reflexão para o enfrentamento da lógica atual dos exames.

A obra Coordenação do Trabalho Pedagógico: do projeto político-pedagógico ao cotidiano da sala de aula termina como começou: analisando criticamente o trabalho pedagógico e ensinando como melhor coordená-lo segundo a pedagogia libertadora, combinada à lógica emancipadora. Assim, chama os educadores para a luta por mudanças, porque há linhas 
de ruptura no horizonte, onde se vislumbra "a formação de sujeitos muito mais apaixonados pelo conhecimento, autônomos, críticos e criativos" (VASCONCELLOS, 2019, p. 305).

Permeado de alertas, conselhos, propostas e roteiros, Coordenação do Trabalho Pedagógico é uma obra para ser lida e relida, mas principalmente para ser praticada. Ela conduz o leitor a compromissos tão urgentes hoje em dia, como ser solidário em meio à competição, ser inclusivo em meio à exclusão e aos distanciamentos, além de "ser mais" ("freirianamente") sem precisar, na escola, ser melhor que todos.

Sendo o público leitor alguém da área da educação, chegará ao final da obra firmando consigo, tacitamente, uma espécie de contrato pedagógico direcionado à mudança das práticas pedagógicas e da relação da escola com a comunidade e sociedade. Se fosse ao gosto do autor, todos partiriam para a ação transformadora da educação e da escola, engajados na luta, dentro de um quadro de superação das contradições inerentes à coordenação do trabalho pedagógico.

Recebido em abril de 2021.

Aprovado em outubro de 2021. 